\title{
The human immunoglobulin A Fc receptor FcaRl: a multifaceted regulator of mucosal immunity
}

\author{
JE Bakema $^{1}$ and M van Egmond ${ }^{1,2}$
}

Immunoglobulin $\mathrm{A}(\lg \mathrm{A})$ is commonly recognized as the most prevalent antibody $(\mathrm{Ab})$ at mucosal sites with an important role in defense by shielding mucosal surfaces from invasion by pathogens. However, its potential to both actively dampen excessive immune responses or to initiate potent proinflammatory cellular processes is less well known. Interestingly, either functional outcome is mediated through interaction with the myeloid IgA Fc receptor Fc $\alpha$ RI (CD89). Monomeric interaction of IgA with Fc $\alpha$ RI triggers inhibitory signals that block activation via other receptors, whereas multimeric $\mathrm{Fc} \alpha \mathrm{RI}$ crosslinking induces phagocytosis, reactive oxygen species production, antigen presentation, $\mathrm{Ab}$-dependent cellular cytotoxicity, and cytokine release. Thus, $\mathrm{Fc} \alpha \mathrm{Rl}$ acts as a regulator between anti- and proinflammatory responses of IgA. As such, the biology of $\mathrm{Fc} \alpha \mathrm{Rl}$, and its multifaceted role in immunity will be the focus of this review.

\section{INTRODUCTION}

Immunoglobulin $\mathrm{A}(\mathrm{Ig} \mathrm{A})$ is the predominant antibody $(\mathrm{Ab})$ class present in mucosal areas, where it has a key role in mucosal defense. ${ }^{1}$ Mucosal surfaces represent a vast interface of over $400 \mathrm{~m}^{2}$ that protects internal tissues from external influences. They are continuously exposed to inhaled or ingested antigens and pathogens, and are colonized by a commensal microbiota, which must be prevented from penetrating the underlying tissues. As such, mucosal homeostasis requires a delicate balance between avoiding disproportionate responses against innocuous antigens, whereas at the same time effective immunological responses against pathogenic microorganisms must be maintained. ${ }^{2}$ Interestingly, depending on the circumstances, IgA is involved in anti- as well as proinflammatory responses, although the view of IgA as an anti- or non-inflammatory Ab commonly prevails. ${ }^{3,4}$

At mucosal sides, IgA is produced in the LP by local plasma cells as dimeric molecules (dimeric IgA; dIgA), containing a joining J chain. It serves as an intermediary, and can bind to the pIgR that is expressed on the basolateral membrane of epithelial cells. Subsequently, it is transported through the epithelial cells and released into the lumen as SIgA. ${ }^{5-7}$ Apical cleavage of $\mathrm{pIgR}$ ensures continual attachment of a part of this receptor-referred to as $\mathrm{SC}-$ which renders increased stability and prevents rapid breakdown of SIgA in the hostile gut lumen milieu. In addition, $1-3 \mathrm{mg} \mathrm{ml}^{-1} \mathrm{IgA}$ is present in the circulation as a monomer, and as such it is the second prevalent $\mathrm{Ab}$ in serum.
Multiple types of cellular IgA receptors have currently been characterized. In addition to $\mathrm{pIgR},{ }^{8} \mathrm{Fc} \alpha / \mu$ receptors, ${ }^{9}$ asialoglycoprotein receptors, ${ }^{10}$ transferrin receptors $(\mathrm{CD} 71),{ }^{11} \mathrm{SC}$ receptors, ${ }^{12}$ and $\mathrm{M}$-cell receptors ${ }^{13}$ have been described that can bind the IgA Fc tail, carbohydrate side chains or accessory molecules such as the J chain and SC. The functions of a number of these receptors have not yet been completely elucidated.

In addition, in humans, a myeloid Fc receptor for IgA (Fc $\alpha$ RI; CD89) has been described. Thus far, FcaRI gene homologs have been identified in primates, horses, cattle, hamsters, gerbils, and rats, but not in mice, which is attributable to a gene translocation. ${ }^{14-19}$ The absence of Fc $\alpha$ RI in mice, which are frequently used for experimental work, has likely influenced the earlier dogma of IgA as an anti-inflammatory Ab class. However, a main role for FcaRI in immune defense is supported, as bacterial evolution has led to the development of proteins that interfere with IgA binding to Fc $\alpha$ RI (e.g., IgA-binding M-like proteins Arp4, Sir22, B-antigen, and members of the staphylococcal superantigen-like proteins family), ${ }^{20}$ resulting in an important evasion strategy for pathogens to escape IgA-mediated phagocytosis. In this review we will therefore address the biology, function and therapeutic potential of Fc $\alpha$ RI.

\section{Fc $\propto$ RI: GENETICS, TRANSCRIPTS, AND PROTEIN STRUCTURE}

FcaRI is a member of the Fc receptor Ig superfamily, although distinct differences can be observed compared with other Fc

${ }^{1}$ Department of Molecular Cell Biology and Immunology, VU University Medical Center, Amsterdam, The Netherlands. ${ }^{2}$ Department of Surgery, VU University Medical Center, Amsterdam, The Netherlands. Correspondence: M van Egmond (m.vanegmond@vumc.nl)

Received 9 June 2011; accepted 8 August 2011; published online 21 September 2011. doi:10.1038/mi.2011.36 
receptors. For instance, the FcaRI gene is located on chromosome 19 (at 19q13.4) and lies within the so-called leukocyte receptor cluster (LRC), ${ }^{21,22}$ whereas other FcR genes, like $F c \gamma R s$ and $F c \varepsilon R I$, map on chromosome $1 .{ }^{23,24}$ The human LRC includes no other Fc receptor genes, but instead it encodes killer cell immunoglobulin-like receptors and leukocyte Ig-like receptors. Fc $\alpha$ RI shows more amino acid (aa) sequence similarities with these receptors than with other human $\mathrm{Fc}$ receptors. ${ }^{25} \mathrm{In}$ addition, the murine paired Ig-like receptor-A that was identified in mice on the basis of the homology with FcaRI, shares sequence similarity with both human FcaRI and killer cell immunoglobulin-like receptors. ${ }^{26}$

FcaRI consists of two extracellular (EC) Ig-like domains of each 206 aa, a 19-aa transmembrane region (TM), which is crucial for association to the signaling FcR $\gamma$-chain, and a short (41 aa) cytoplasmic tail. The two EC domains are folded with an angle of approximately $90^{\circ}$ to each other. The Fc $\alpha$ RI gene (FCAR) coding for this protein consists of five exons. The first two exons encode the leader peptide (S1, $34 \mathrm{bp}$, and S2, 36 bp), whereas exons 3 (291 bp) and 4 (288 bp) code for $\mathrm{EC} 1$ and EC2, respectively. The transmembrane and intracellular domains are both encoded by exon 5 (215bp). ${ }^{27-29}$ Furthermore, a 78-bp insertion sequence (S3) between S2 and EC1 has been reported. ${ }^{30}$ The Fc $\alpha$ RI promoter was identified in a 929-bp fragment of FcaRI 5 '-flanking sequence, in which tissue-specific gene expression is regulated by $259 \mathrm{bp}$, proximal to the translation initiation site. ${ }^{31}$ The sequence between 59 and $197 \mathrm{bp}$, downstream of the major transcription start site, is essential for promoter activity and contains multiple potential binding sites for transcription factors ((C/EBP) binding sites, nuclear factor- $\mathrm{\kappa B}$ binding site, Spl site, Ets family protein consensus binding site, and a Myb binding site), which have been reported to function in myeloid-specific gene expression. ${ }^{32,33}$ The core protein has a predicted molecular weight of $30 \mathrm{kDa}$. However, Fc $\alpha$ RI that is expressed on the cell surface has an apparent molecular weight between 50 and $75 \mathrm{kDa}$, with the exception of eosinophil Fc $\alpha$ RI, which runs between 70 and $100 \mathrm{kDa}$. This heterogeneous pattern of surface-expressed Fc $\alpha \mathrm{RI}$ is a consequence of both $\mathrm{N}$ - and $\mathrm{O}$-glycosylation. ${ }^{34-36}$

Several isoforms have been described in primary cells in addition to the full-length Fc $\alpha$ RI protein. Fc $\alpha$ RIa.2 bears deletion of 66 aa in EC2, and it is the only isoform expressed on alveolar macrophages, which might have a physiological relevance in IgA-mediated host defense in the lung. ${ }^{37}$ In addition, the isoform Fc $\alpha \mathrm{Rb}$ lacks the transmembrane and intracellular domain, which is replaced by 23 new aa. This is the consequence of alternative splicing that skips the 3 -splice site at the end of the EC2 exon, resulting in the insertion of 23 new aa before the stop codon. FcaRb has been described in both neutrophils and eosinophils. ${ }^{38}$ Although Fc $\alpha$ Rb can be expressed on the cell membrane-which is probably due to the 23 aa insertion-it is presented mainly as a soluble form. Furthermore, cell-surface-expressed $\mathrm{Fc} \alpha \mathrm{Rb}$ is unable to associate with $\mathrm{FcR} \gamma$-chain and therefore unable to exert cellular signaling after binding to IgA complexes. This suggests that full-length FcaRI and soluble Fc $\alpha \mathrm{Rb}$ on granulocytes may compete for IgA binding.
As such, Fc $\alpha$ Rb may downregulate signaling via full-length Fc $\alpha$ RI. A Fc $\alpha$ Rb alternative spliced transcript (Fc $\alpha$ Rb $\Delta S 2)$ has been described as well, in which the leader peptide 2 is deleted. However, it is not clear whether this transcript is translated into a functional protein. A second soluble FcaRI has been described that is specifically expressed by monocytes, and which is the result of crosslinking of full-length FcaRI, which triggers FcR $\gamma$-chain-dependent shedding. ${ }^{39}$ Interestingly, release of soluble FcaRI-which is likely due to proteolytic cleavage-is induced by IgA aggregates, suggesting a regulatory effect on Fc $\alpha$ RI effector functions. A $2-3 \mathrm{kDa}$ smaller protein variant of fulllength Fc $\alpha$ RI (with a core protein of $29-30 \mathrm{kDa}$ ) was described in neutrophils, as well. ${ }^{40}$ The nature of this variant is not clear at present.

In addition, mRNA encoding Fc $\alpha$ RIa. 3 that lacks EC2 has been identified in granulocytes and monocytes. ${ }^{41}$ Cells, which were transfected with this variant, were able to bind SIgA, but not serum IgA. Furthermore, tumor necrosis factor- $\alpha$ specifically increased or decreased Fc $\alpha$ RIa. 3 transcripts compared with full-length FcaRIa.1 transcripts in neutrophils or monocytes, respectively. ${ }^{42}$ Other alternative spliced transcripts have been described on mRNA, but not at protein level, in primary cells or cell lines. ${ }^{34,37,41-44}$ These include the $\Delta S 2$ transcript, in which the leader peptide 2 is deleted, $\Delta \mathrm{S} 2 \mathrm{EC} 1$, in which both leader peptide 2 and $\mathrm{EC} 1$ are eliminated, and transcripts with (part of) EC2 deletions, including $\triangle$ S2EC2 (deletion of leader peptide 2 and EC2), $\triangle \mathrm{S} 266 \mathrm{EC} 2$ (deletion of part leader peptide 2 and $66 \mathrm{bp}$ of EC2), and $\Delta$ S274EC2 (missing leader peptide 2 and 74 bp of EC2). Biological significance is not yet completely understood, although different levels of full-length and alternative spliced FcaRI transcripts have been documented in several diseases. ${ }^{30,42}$ For example, neutrophils from patients suffering from pneumonia have lower Fc $\alpha$ RIa.3 transcripts, whereas monocytes from patients with IgA nephropathy solely express full-length FcaRI. As such, protein isoforms may diversify FcaRI structure and function in immunoregulation of IgAmediated host defense.

Several single-nucleotide polymorphisms (SNPs) have been described in the FCAR gene as well. ${ }^{29,31,45-51}$ These constitute three different SNPs within the FCAR gene promotor region, namely $-340 \mathrm{G} / \mathrm{A},-311 \mathrm{~T} / \mathrm{C}$, and $-142 \mathrm{~T} / \mathrm{C}$, of which the latter two show lower promoter activity within the $\mathrm{T}$ allele. Furthermore, two non-coding SNPs (324A/G and 363A/G) are documented within the EC1. The SNP 376G/A results in an aa change from aspartic acid into asparagine. The effect of this variation on IgA binding is not known, although it is located closely to the ligand binding site. ${ }^{52}$ Finally, a functional SNP has been identified in the intracellular domain $(844 \mathrm{~A} / \mathrm{G})$, which results in an aa transition from serine to glycine (S248-G248). ${ }^{50}$ IgA-mediated crosslinking of neutrophil FcaRI-G248 triggered significantly more interleukin (IL)-6 release than equivalent crosslinking of the FcaRI-S248 variant. Remarkably, only FcaRI-G248, is capable of inducing cytokine release in the absence of FcR $\gamma$-chain, which is presumed due (at least in part) to its ability to interact directly with the Src family member Lyn, an important component of the FcaRI signaling cascade. ${ }^{50}$ 
Association of FCAR gene polymorphisms with diseases has been investigated to some extent. Until now, none of the SNPs were associated with allergy, ${ }^{52}$ but altered susceptibility to aggressive periodontitis (324A/G SNP) ${ }^{48}$ systemic lupus erythematosus (844A/G SNP) ${ }^{50}$ and chronic HCV infection $\left(-311 \mathrm{~T} / \mathrm{C}\right.$ and $-142 \mathrm{~T} / \mathrm{C}$ SNPs) have been described. ${ }^{49}$ Furthermore, the (844A/G SNP) influences susceptibility to systemic lupus erythematosus, but not systemic sclerosis or rheumatoid arthritis, ${ }^{50,53}$ whereas controversy exists for FcaRI polymorphisms in relation to susceptibility to $\operatorname{IgA}$ nephropathy. ${ }^{31,46,54}$

\section{EXPRESSION AND MODULATION}

FcaRI expression is already observed at the promyelocyte stage in differentiation, and is restricted to cells of the myeloid lineage, including neutrophils, eosinophils, monocytes, and several macrophage subsets (e.g., alveolar, tonsilar, and splenic, but not small intestine macrophages). Fc $\alpha \mathrm{RI}$ is furthermore expressed on Kupffer cells and on interstitial, CD34 ${ }^{+}$-derived dendritic cells (DCs) and monocyte-derived DCs (although the latter may be reflected by FcaRI expression on monocytes, which decreases during DC differentiation). ${ }^{34-37,55-59}$ Expression has recently been described on human platelets as well, whereas Fc $\alpha$ RI is not expressed on mast cells or basophils. ${ }^{60}$ Fc $\alpha$ RI expression is constitutive and independent of its ligand, which is demonstrated in IgA-deficient patients who still express Fc $\alpha$ RI. ${ }^{61}$ However, depending on the cell type, expression and function of FcaRI can be modulated by lipopolysaccharide, chemoattractants, inflammatory cytokines, or adapter protein, binding to the intracellular domain of Fc $\alpha$ RI. ${ }^{25,62}$ For instance, upregulation is induced by IL- $1 \beta$, tumor necrosis factor- $\alpha$, granulocyte-macrophage-colony stimulating factor, and IL-8, ${ }^{63-66}$ whereas expression is downregulated by transforming growth factor- $\beta$, interferon- $\gamma$, or the ligand polymeric IgA. ${ }^{67,68}$ Upregulation of neutrophil Fc $\alpha$ RI expression levels can be the result from either de novo synthesis or transport from intracellular stores to the cell surface. ${ }^{40}$ Full-length FcaRI is present in both secretory and tertiary granules, whereas the $2-3 \mathrm{kDa}$ smaller variant (core protein of $29-30 \mathrm{kDa}$ ) is also present in tertiary granules. As these granules are differently mobilized during neutrophil activation or inflammatory responses, distinct biological functions for Fc $\alpha$ RI are suggested, but this has not yet been investigated thoroughly. Tissue distribution of Fc $\alpha$ RI is mostly defined by the presence of neutrophils and few emigrated macrophages. ${ }^{69}$ These cells are evident as clusters in tonsils and appendix, and are scattered in varying numbers in lymph nodes, kidneys, livers, intestinal mucosa, bronchoalveolar lavages, or peritoneal fluid. Inflamed intestines display major influxes of Fc $\alpha$ RIpositive neutrophils. The level of Fc $\alpha$ RI on neutrophils was similar in tissue compared with blood neutrophils, whereas FcaRI expression on monocytes was much lower in tissues than in blood. Altered Fc $\alpha$ RI expression has been reported in diseases such as ankylosing spondylitis, allergic diseases, human immunodeficiency virus (HIV) infection, or bacterial infections. ${ }^{36,70-72}$

\section{LIGAND BINDING}

Although all forms of IgA are ligands for FcaRI, the binding capacities differ. Although monomeric IgA and dimeric IgA are capable of binding FcaRI with moderate affinity $\left(\mathrm{Ka}=\sim 10^{6} \mathrm{M}^{-1}\right)$ in the boundaries of $\mathrm{C} \alpha 2$ and $\mathrm{C} \alpha 3$, IgA-immune complexes bind avidly. ${ }^{73-77}$ Furthermore, because of the partial overlap of the IgA binding site for either Fc $\alpha$ RI or pIgR, interaction of SIgA to Fc $\alpha \mathrm{RI}$ is (partly) hampered because of steric hindrance of SC. ${ }^{75,78-80}$ SIgA binding is however increased when complement receptor 3 functions as coreceptor.

Crystallographic studies demonstrated that one IgA molecule can simultaneously bind two FcaRI molecules (Figure 1) ${ }^{75,76}$ This is in contrast to Fc $\gamma$ RIII and FceRI, for which a 1:1 stoichiometry with their respective ligands was described, again emphasizing dissimilarities between FcaRI and other members of the Fc receptor family. ${ }^{81-85}$ Moreover, the IgA binding site on FcaRI is located in EC1 (Figure 1, depicted as yellow aa), ${ }^{75,76,79}$ which is different compared with FceRI and Fc $\gamma$ Rs, as these FcRs bind their ligands in EC2. Residues Y35 (in the BC loop), R52, R53, L54, K55 (in the D strand), F56, W57, N58 (in the DE loop), Y81, R82, I83, G84, H85, and Y86 (in the FG loop) within EC1 are involved in IgA binding. ${ }^{73-75}$ Surprisingly, alternative spliced Fc $\alpha$ RI, which lacks EC2, does not bind serum IgA, but binds SIgA comparable to full-length Fc $\alpha$ RI. ${ }^{41}$

Residues within IgA that are involved in $\mathrm{Fc} \alpha \mathrm{RI}$ binding (Figure 1, depicted as blue aa) are L256, L257, and L258 in the $\alpha$-helix of the AB loop of C $\alpha 2$. Within C $\alpha 3$ E348 (A-strand), R382, L384 (C-strand), S387, E389 (CC' loop), M433, H436 (F-strand), E437, A438, L439, P440, L441, A442 (FG loop), F443, T444, and Q445 (G strand) are involved. ${ }^{75,86}$ Immune complexes with optimal binding contain five to six molecules of IgA per complex. ${ }^{87}$ A number of conformational changes have been observed within the Fc $\alpha$ RI-EC1 domain (in the D-strand, DE and FG loop) after binding to IgA, but the approximately $90^{\circ}$ orientation of the two EC domains do not change significantly. ${ }^{75}$ Furthermore, both Fc $\alpha$ RI and IgA are heavily glycosylated proteins. Fc $\alpha$ RI harbors six $N$-glycosylation sites and several putative $O$-linked glycosylation sites, and it has been demonstrated that deglycosylation of Fc $\alpha$ RI N58 increases IgA binding. ${ }^{88}$ By contrast, IgA Fc glycosylation is not critical for binding to Fc $\alpha$ RI ${ }^{88-90}$ Several monoclonal Abs (mAbs) have been described that bind Fc $\alpha$ RI (Figure 1, right part) in EC1 (My43, 2E6, 2D11, 7G4, 2H8, and MIP8a), EC2 (A59, A77, A62, and 7D7), or have binding sites in both ECs (A3). ${ }^{34,91,92}$ All $\mathrm{EC} 1$ recognizing $\mathrm{mAbs}$ block IgA binding, whereas $\mathrm{mAb} A 62$ recognizes low glycosylated Fc $\alpha$ RI. Recently, it was described that the pentraxin C-reactive protein binds to FcaRI, which induces cellular activation. C-reactive protein binds to distinct regions of Fc $\alpha$ RI compared with IgA, suggesting simultaneous binding of both molecules to Fc $\alpha$ RI. ${ }^{93}$

Ligand binding to $\mathrm{F} c \alpha \mathrm{RI}$ is regulated via a mechanism referred to as inside-out signaling, which entails that cytokine stimulation of cells rapidly, modulates binding capacity in response to intracellular signals, without affecting receptor expression levels. ${ }^{94-98}$ Experiments with eosinophils, monocytes, and 


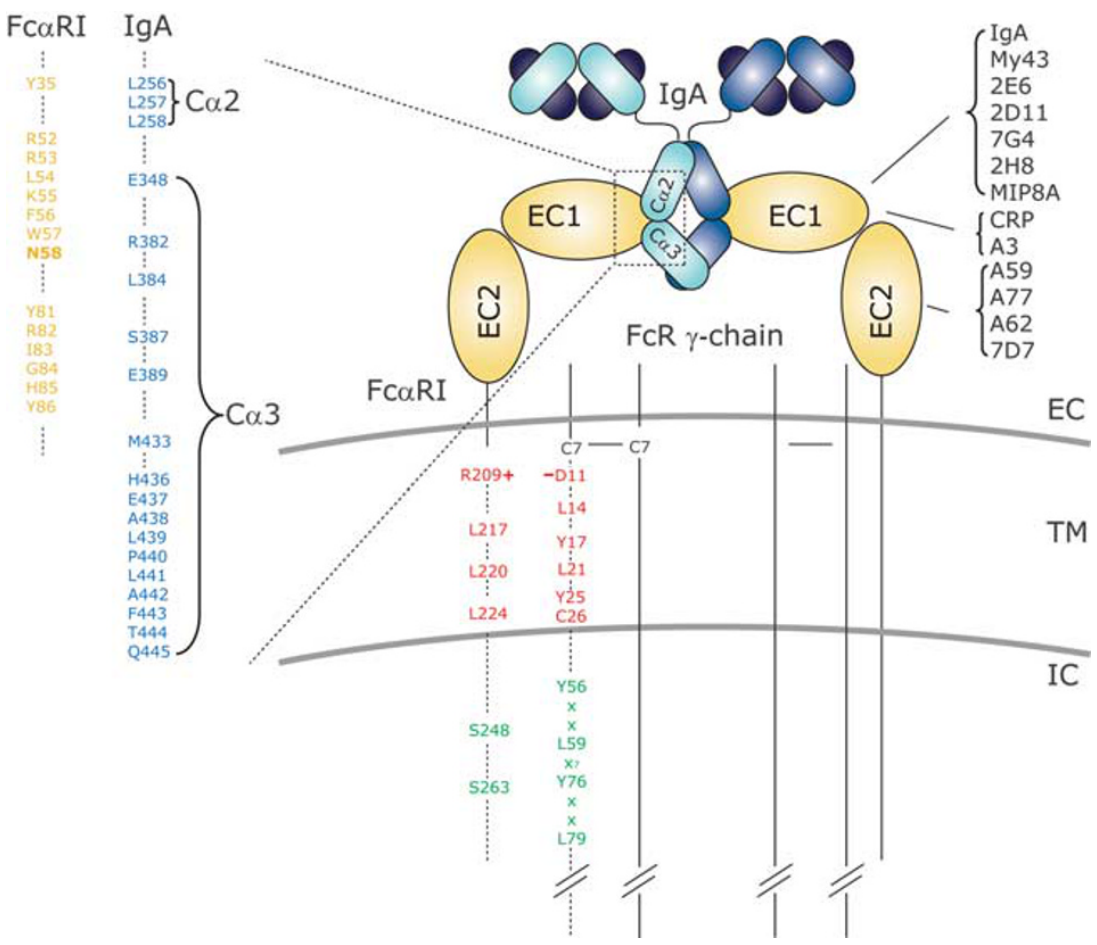

Figure 1 Schematic representation of the Fc $\alpha$ RI-FcR $\gamma$-chain complex, binding immunoglobulin A (IgA) in a 2:1 stoichiometry. Two Fc $\alpha$ RI bind each IgA-Fc part at the $\mathrm{C} \alpha 2$ and $\mathrm{C} \alpha 3$ junction via extracellular (EC) 1. Amino acids (aa) involved in ligand-receptor binding are depicted in yellow for Fc $\alpha \mathrm{RI}-$ $\mathrm{EC} 1$ and in blue for aa in $\mathrm{C} \alpha 2$ and $\mathrm{C} \alpha 3$ of IgA (left part of figure). Deglycosylation of N58 in Fc $\alpha \mathrm{RI}-\mathrm{EC} 1$ (bold) increases IgA binding. Amino acids in the transmembrane regions (TMs) of Fc $\alpha \mathrm{RI}$ and a FCR $\gamma$-chain homodimer, involved in complex formation, are depicted in red, whereas aa involved in signaling are shown in green. Fc $\alpha \mathrm{RI}$ intracellular (IC) serine 248 and 263, respectively, modulates FcR $\gamma$-chain independent interleukin (IL)-6 production and inside-out signaling. FcR $\gamma$-chain intracellular immunoreceptor tyrosine-based activation motif (ITAM) consensus (YxxLx $\left.x_{7} Y x x L\right)$ is shown, as well as the disulfide bond between two cysteines at position 7 (solid line). Monoclonal antibodies and C-reactive protein recognizing different ECs of Fc $\alpha \mathrm{RI}$ are depicted (right part).

transfectants demonstrated that FcaRI shows low capacity to interact with $\operatorname{IgA}$-immune complexes in a resting state, but ligand binding capacity increases profoundly after stimulation with cytokines such as granulocyte-macrophage-colony stimulating factor, and IL-4 or IL-5. As such, FcaRI becomes primed, but surface receptor expression is not augmented. ${ }^{96-98}$ Insideout signaling critically depends on the intracellular domain of FcaRI and on the presence of an intact cytoskeleton, but it does not require FcR $\gamma$-chain. ${ }^{96,97}$ In more detail, phosphorylation of serine 263 (Figure 1, depicted in green), and activation of phosphatidylinositol 3-kinase (PI3K) and its downstream target protein kinase $\mathrm{C}$ are essential in switching inactive FcaRI into an active, ligand binding receptor (Figure 2a). Simultaneously, cytokine stimulation induces binding of the serine-threonine phosphatase protein protein phosphatase $2 \mathrm{~A}$ to the intracellular domain of Fc $\alpha$ RI, which results in dephosphorylation of the Fc $\alpha$ RI intracellular domain, allowing binding of IgA-immune complexes. ${ }^{98}$ Whether FcaRI priming is a result of enhanced lateral movement (avidity) and/or conformational changes within the receptor (affinity), as described for integrins, ${ }^{99}$ is currently unknown. It is not clear whether Fc $\alpha$ RI on neutrophils needs priming as well, as activation of neutrophils during isolation has, as of yet, precluded these experiments. However, neutrophils of patients suffering from active, ongoing derma- titis herpetiformis (DH) demonstrate increased ability to bind IgA, without increased receptor expression, which is consistent with a pattern of receptor priming. ${ }^{100}$ This suggests that priming is the result of ongoing mucosal inflammatory responses and concomitantly systemic cytokine release in patients with dermatitis herpetiformis.

\section{IgA-MEDIATED Fc $\alpha$ RI SIGNALING AND CELLULAR FUNCTIONING}

Binding of IgA-immune complexes (containing either monomeric IgA or dimeric $\operatorname{Ig} \mathrm{A}$ ) induces proinflammatory responses, which requires association of FcaRI with the FcR $\gamma$-chain subunit. ${ }^{101-103}$ Two basic aspects are essential for tethering Fc $\alpha$ RI and FcR $\gamma$-chain into a stable Fc $\alpha$ RI-FcR $\gamma$-chain complex. First, dimerization of two $\gamma$-chains-through disulfide bond between two cysteines-is required, and second, association between the positively charged arginine 209 (R209) in the TM of Fc $\alpha$ RI and an opposite negatively charged aspartic acid 11 (D11) in the TM of FcR $\gamma$-chain is essential (Figure 1, depicted in red). Moreover, it was demonstrated that orientation of the positive charge within the TM of Fc $\alpha$ RI into the vicinity of the FcR $\gamma$-chain dimer is important. ${ }^{104}$ In addition, two leucines (L14 and L21), two tyrosine (Y17 and Y25), and a cysteine at position $26\left(\mathrm{C}_{26}\right)$, within FcR $\gamma$-chain, as well as three leucines on position 217, 
a Inside-out signaling (priming)

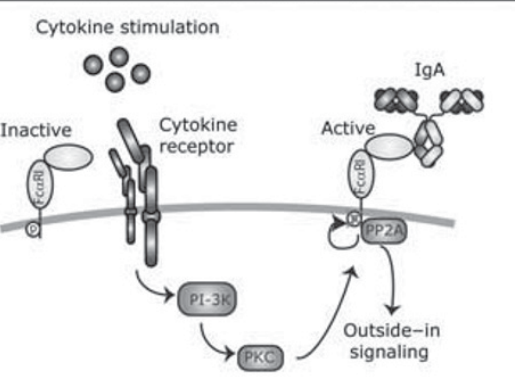

b Outside-in signaling (effector functions)

ITAM

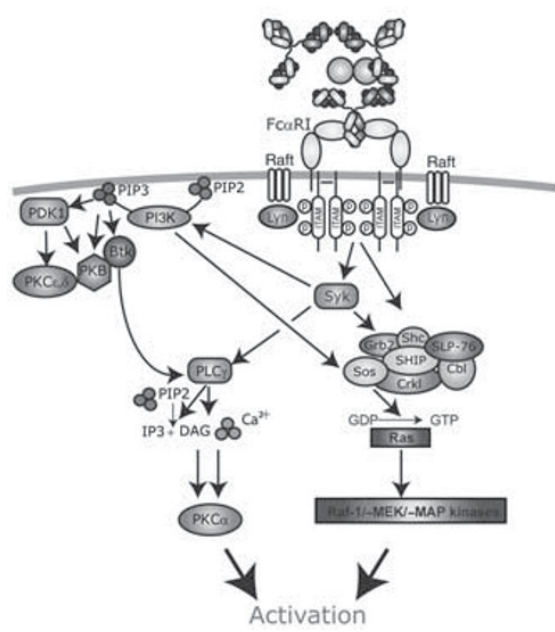

ITAMi

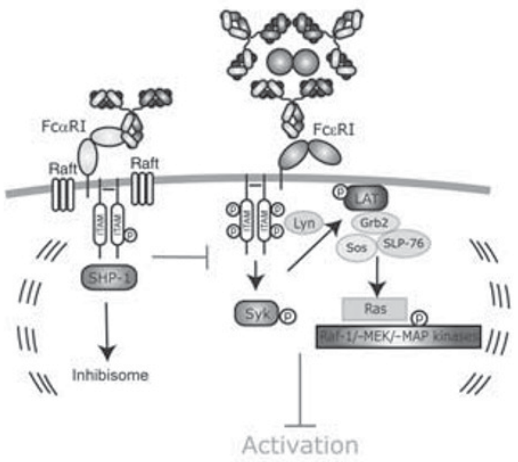

Figure 2 Simplified scheme of signaling pathways involved in Fc $\alpha$ RI functioning. (a) Inside-out signaling or priming of Fc $\alpha$ RI. The intracellular domain of $\mathrm{Fc} \alpha \mathrm{RI}$, an intact cytoskeleton, phosphorylation of serine 263, phosphatidylinositol 3 kinase (PI3K), and its downstream target protein kinase $\mathrm{C}(\mathrm{PKC})$ and serine/threonine phosphatase protein protein phosphatase $2 \mathrm{~A}$ (PP2A) are involved in switching inactive Fc $\alpha \mathrm{RI}$ into an active, ligand binding receptor after cytokine stimulation. (b, Left) Crosslinking of $\mathrm{Fc} \alpha \mathrm{RI}$ by immunoglobulin A (IgA)-immune complexes induces redistribution of Fc $\alpha R I$ to plasma membrane rafts. Src kinase Lyn phosphorylates the tyrosines within the associated FcR $\gamma$-chain-immunoreceptor tyrosine-based activation motif (ITAM). These then serve as "docking" sites for recruitment of B lymphocyte kinase (BIk), Syk, phospholipase (PLC)- $\gamma$, Shc, and growth factor receptor-bound protein 2 (Grb2), which facilitates activation of multiple (and subsequential) targets such as PI3K, PLC- $\gamma$, and components of a Grb2 containing multimolecular adapter protein complex. This results in cellular functions such as phagocytosis, Ab-dependent-cellular cytotoxicity, respiratory burst, degranulation, antigen-presentation, and release of cytokines and inflammatory mediators. (Right) Triggering FcaRI with monomeric serum IgA (not crosslinking Fc $\alpha \mathrm{RI}$ ) transduces inhibitory signals through Fc $\alpha \mathrm{RI}$-FcR $\gamma$-chain complex via inhibitory capacity through FcR $\gamma$-chain ITAM (ITAMi), which downregulates other activating Fc receptors. The inhibitory signal involves recruitment of Src homology region 2 domain-containing phosphatase-1 (SHP-1) to FcaRI, and formation of inhibisome clusters (dotted lines), which impair phosphorylation of Syk, LAT, and ERK. Ca ${ }^{2+}$, calcium; Cbl, Casitas B-lineage lymphoma; DAG, diacylglycerol; GDP, guanosine diphosphate; GTP, guanosine triphosphate; LAT, linker of activated T cells; $p$, phosphate; PIP2, phosphatidylinositol 4,5-bisphosphate; PIP3, phosphatidylinositol $(3,4,5)$-triphosphate; SLP-76, SH2 domain containing leukocyte protein of $76 \mathrm{kDa}$; SHIP, Src homology-2-containing inositol 5'-phosphatase.

220, and 224, within Fc $\alpha$ RI TM, contribute to the stabilization of the FcoRI-FcR $\gamma$-chain complex ${ }^{105,106}$ (Figure 1, depicted in red). In vivo studies in FcaRI transgenic-FcR $\gamma$-chain knockout mice demonstrate that FcR $\gamma$-chain association is essential for Fc $\alpha$ RI surface expression. ${ }^{103}$ However, Fc $\alpha$ RI expression in the absence of FcR $\gamma$-chains (FcaRI “ $\gamma$-less") was observed in transfected cell lines, and selective human monocyte and neutrophil populations. ${ }^{107-109}$ Functionality of Fc $\alpha$ RI " $\gamma$-less" receptors is limited to ligand binding (inside-out signaling) and receptor recycling via early endosomes, although FcaRI-Gly248 was shown to trigger IL-6 production in the absence of FcR $\gamma$-chain. ${ }^{50}$
The mechanism of Fc $\alpha$ RI binding to FcR $\gamma$-chain underscores the difference with other FcRs, but shows similarities with members of the LRC family. ${ }^{22,74}$ Within the LRC family, an N-terminal positively charged arginine is highly conserved among all activatory receptors, with the exception of killer cell activatory receptors, which bear a positively charged lysine in the center of their TM. Interestingly, killer cell activatory receptors interact with the signaling molecule DAP12, whereas other LRC stimulatory receptors associate (like Fc $\alpha \mathrm{RI}$ ) with the FcR $\gamma$-chain. ${ }^{110,111}$ In addition, paired Ig-like receptor-A associates with the FcR $\gamma$-chain via an transmembrane $\mathrm{N}$-terminal arginine. By contrast, FcR $\gamma$-chain association of other activating Fc receptors is based 
on the residues in the C-terminal part of their TMs. ${ }^{112-114}$ For example, Fc $\gamma \mathrm{RI}$ requires a domain of $10 \mathrm{aa}$, including an asparagine and $\mathrm{Fc} \varepsilon \mathrm{RI}$, and $\mathrm{F} c \gamma \mathrm{RIII}$ require a $\mathrm{C}$-terminal aspartic acid for FcR $\gamma$-chain association.

Crosslinking of Fc $\alpha \mathrm{RI}$ by IgA-immune complexes induce FcR $\gamma$-chain independent redistribution of FcaRI to plasma membrane rafts. ${ }^{115}$ Furthermore, both the tyrosine kinase Bruton's tyrosine kinase and $s r c$ family kinase Lyn are recruited to these signaling platforms. Fc $\alpha$ RI crosslinking furthermore initiates immunoreceptor tyrosine-based activation motif (ITAM)-dependent signaling of the Fc $\alpha$ RI-associated FcR $\gamma$ chain (Figure 2b, left part). ${ }^{23,116}$ The FcR $\gamma$-chain ITAMs consists of a conserved stretch of aa of paired tyrosines and leucines in a consensus sequence ( $\mathrm{YxxLx}_{7} \mathrm{YxxL}$, Figure 1, depicted in green). Src kinase Lyn phosphorylates the tyrosines within the associated FcR $\gamma$-chain-ITAM. These then serve as the "docking" sites for recruitment of other tyrosine kinases, including B lymphocyte kinase and the Src homology 2 (SH2)-domaincontaining proteins Syk, phospholipase C- $\gamma$, Shc, and growth factor receptor-bound protein 2, which facilitates the activation of multiple targets such as PI3K (with downstream PDK1, protein kinase $\mathrm{C} \varepsilon$ and $\delta, \mathrm{PKB} \alpha$, and Bruton's tyrosine kinase activation) and phospholipase C- $\gamma$ (with downstream release of IP3 and diacylglycerol to trigger calcium release and activation of calcium- and diacylglycerol-dependent protein kinase $\mathrm{C} \alpha$ ) (Figure 2b, left part). ${ }^{115,117-120}$ Of note, these pathways are interconnected, for example, Bruton's tyrosine kinase can potentiate calcium signaling-via phospholipase $\mathrm{C} \gamma$-but is activated by binding to the PI3K product phosphatidylinositol $(3,4,5)$-triphosphate via its PH domain. Moreover, Src family kinases, that are activated after Fc $\alpha$ RI stimulation, also induces the formation of multimolecular adapter protein complexes consisting of the adapter growth factor receptor-bound protein 2-which is constitutively bound to Sos-and recruited upon phosphorylation of Shc. Furthermore, this complex contains Src homology-2-containing inositol 5' - phosphatase, Casitas B-lineage lymphoma, SH2 domain containing leukocyte protein of $76 \mathrm{kDa}$, and Crkl. ${ }^{121}$ Through this adapter complex, GDP-Ras is exchanged to active GTP-Ras by Sos (a guanine nucleotide exchange factor), that is activated by PI3K), which, in turn, activates Raf-1-MEK-MAP serine-threonine kinases by sequential phosphorylation. The interconnected signaling pathways couple upstream FcR $\gamma$-chain ITAM phosphorylation to different cellular processes, such as gene expression by activation of several transcription factors (including nuclear factor- $\kappa \mathrm{B}, \mathrm{AP}-1$, and Sp1), phagocytosis, Ab-dependent-cellular cytotoxicity, respiratory burst, degranulation, antigen presentation, and release of cytokines and inflammatory lipid mediators. ${ }^{103,109,119-130}$ Of note, depending on cell type or cell stimulation, Fc $\alpha$ RI activation may trigger cell type-specific signaling and functional responses.

Intriguingly, it was demonstrated that non-targeted monomeric serum IgA (not crosslinking Fc $\alpha$ RI) transduces inhibitory signals through the Fc $\alpha$ RI-FcR $\gamma$-chain complex, which downregulates IgE- or IgG-, Fc-receptor-mediated phagocytosis, chemotaxis, bacterial activity, oxidative burst activity, and cytokine release. ${ }^{131-139}$ The underlying molecular mechanisms involves ERK-dependent recruitment of tyrosine phosphatase Src homology region 2 domain-containing phosphatase- 1 and Fc $\alpha$ RI to lipid rafts (Figure 2b, right part). ${ }^{131,140}$ In a second step, ligation of the activating Fc receptor results in colocalization with FcaRI and Src homology region 2 domain-containing phosphatase- 1 in rafts. These assembled proteins form intracellular structures called "inhibisomes," which induce impairment of Syk, LAT, and ERK phosphorylation and functionality of activating Fc receptors. Formation of inhibisomes requires $\mathrm{Src}$ homology region 2 domain-containing phosphatase-1-dependent depolarization of actin. Sustained aggregation of Fc $\alpha$ RI by multimeric ligands by contrast stimulates cell activation by recruiting high amounts of Syk (described above), whereas Src homology region 2 domain-containing phosphatase- 1 binding is aborted. ${ }^{131}$ The inhibitory capacity through FcR $\gamma$-chain ITAM is referred to as ITAMi, which differs from the classical immunoreceptor tyrosine-based inhibitory motif signaling of inhibitory Fc receptors, which requires co-aggregation with the activatory Fc receptor. ${ }^{23,141}$ Thus, both IgA-induced activating and inhibitory signals depend on FcaRI-FcR $\gamma$-chain ITAM, but differ in the recruitment of tyrosine kinases versus tyrosine phosphatases, respectively, (Figure 2b). As such, it has been proposed that crosslinking of Fc $\alpha$ RI during infection with IgA-opsonized pathogens results in proinflammatory responses, whereas naturally occurring serum IgA (not complexed with an antigen) induces inhibitory signals through FcaRI to dampen excessive immune responses (initiated by other Ig-immune complexes).

\section{Fc $\alpha R I$ AND IgA IN MUCOSAL IMMUNOLOGY}

Only few FcaRI-positive cells are observed in mucosal areas in homeostatic conditions. For instance, intestinal macrophages lack Fc $\alpha$ RI expression, ${ }^{58}$ which is consistent with an anti-inflammatory role of IgA to protect mucosal integrity. Furthermore, mucosal Langerhans cells do not express Fc $\alpha$ RI. However, low FcaRI levels were observed on in vitro cultured monocyte-derived DCs, which resemble interstitial DC human epithelial interstitial-type DC. A study by Heystek et al. ${ }^{59}$ demonstrated low level expression of Fc $\alpha$ RI on immature monocyte-derived DCs as well. Crosslinking of FcaRI led to internalization of (serum) IgA complexes and antigen presentation through the major histocompatibility complex class II pathway, but not via major histocompatibility compatibility class I cross-presentation, which resulted in monocyte-derived DCs maturation and production of IL-10..$^{57,120,142}$ Because IL10 mediates IgA isotype switching, ${ }^{143}$ a role for Fc $\alpha$ RI-positive DC in mounting specific immune responses is supported. However, it should be noted that, although FcaRI is able to mediate efficient antigen presentation in FcaRI-expressing transfectants-, ${ }^{109}$ uptake of IgA immune complexes by DCs, expressing low levels of Fc $\alpha \mathrm{RI}$, led to poor antigen presentation. ${ }^{144}$ Efficient uptake of SIgA was demonstrated, which was partially blocked by anti-mannose receptor $\mathrm{mAb}$, but not by anti-FcaRI blocking mAbs. This indicated that monocytederived DCs did not internalize SIgA via FcaRI, but through 

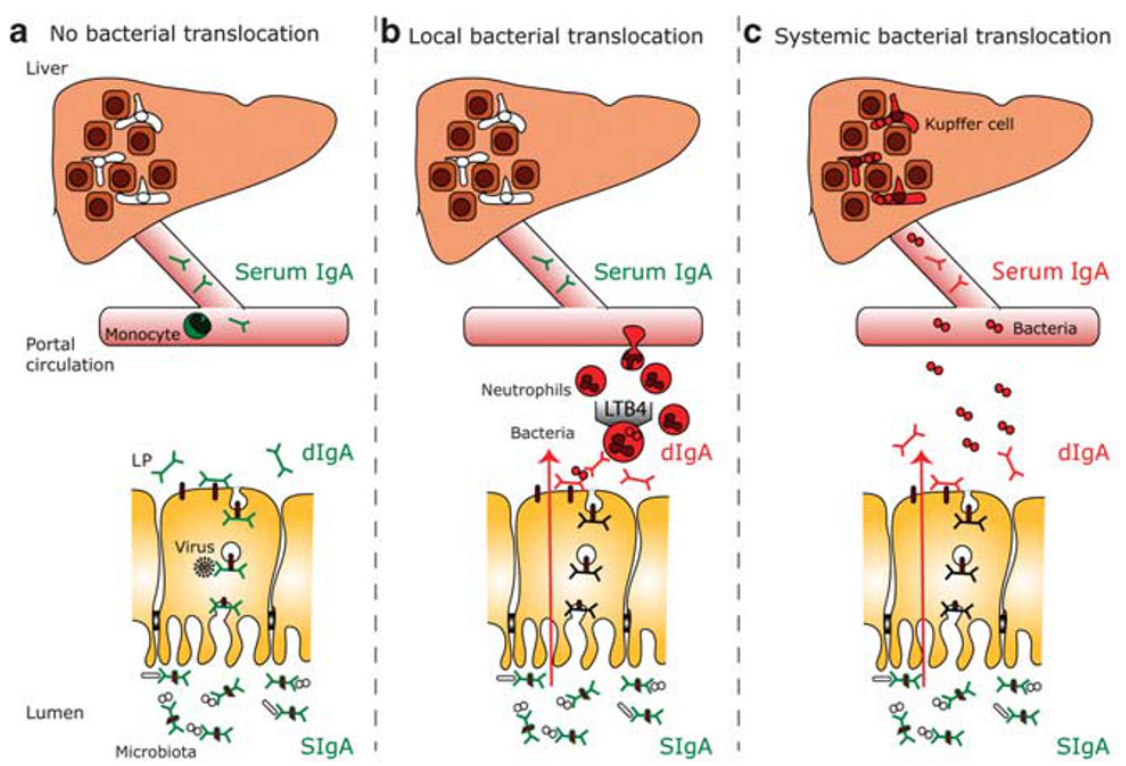

Figure 3 Model for the role of Fc $\alpha$ RI in mucosal immunity. In humans, immunoglobulin A $(\lg A)$ is expressed in three different forms. (a) In homeostatic conditions dimeric $\lg \mathrm{A}(\mathrm{dlg} \mathrm{A})$ functions as intermediary molecule that is secreted as SIgA, which inhibits bacterial invasion. Monomeric serum IgA functions as anti-inflammatory molecule through targeting FcaRl-inhibitory capacity through FcR $\gamma$-chain ITAM (ITAMi) signaling. (b) When microorganisms have been able to breach the epithelial barrier, dlgA can opsonize these pathogens. Recruited neutrophils that express FcaRI will clear the infection through phagocytosis and release of leukotrien B4 (LTB4, via active immunoreceptor tyrosine-based activation motif (ITAM) signaling), which may lead to a self-controlled positive feedback loop, until pathogens have been eliminated. Hence, in case of local bacterial translocation, dlgA represents a proinflammatory molecule and functions as the second line of innate mucosal immune defense. (c) Finally, pathogens that have entered the portal circulation are opsonized by serum IgA, and subsequently phagocytosed by FcaRI-positive Kupffer cells. As such, serum IgA can function as proinflammatory antibody when systemic bacterial translocation occurs, and interaction with Fc $\alpha$ RI on Kupffer cells represent a third line of defence at the interface of mucosal and systemic immunity. Green, non- or anti-inflammatory and red, proinflammatory.

interaction with carbohydrate-recognizing receptors. Because uptake of SIgA was not accompanied by DC maturation, it was suggested that internalization of SIgA by DC might have a role in maintaining self-tolerance against commensal bacteria. SIgA furthermore has an important role as the first line of defense by preventing penetration of mucosal surfaces by microorganisms or foreign antigens (Figure 3a). ${ }^{1}$ SIgA inhibits adherence of microorganisms, can agglutinate microbes, and interfere with bacterial motility by interacting with their flagella. Moreover, SIgA neutralizes bacterial products such as enzymes and toxins. However, opsonic activity is poor compared with dIgA or serum IgA as a result of (partial) blockage of the Fc $\alpha$ RI binding site by SC, which is consistent with a more anti-inflammatory role of SIgA. By contrast, both $\operatorname{dIgA}$ and serum IgA have a dual role in immunity, as they can show both anti- and proinflammatory roles.

In homeostatic conditions, $\operatorname{dg} \mathrm{A}$ serves as an intermediary that is transported through epithelial cells and released as SIgA. Although antibodies in general have a limited benefit against intracellular pathogens, dIgA can passively neutralize intracellular viruses because of trans-epithelial cell transport by intersecting virus particles and interfering with virus replication or assembly. IgA-virus complexes are subsequently removed via the lumen (Figure 3a). It was demonstrated that addition of specific anti-viral IgA to the basolateral surface of polarized epithelial cells in vitro decreased virus titers of Sendai virus, rotavirus, influenza, or HIV. ${ }^{145-149}$ Furthermore, culture with polymeric IgA against toxin A of Clostridium difficile prevented destruction of epithelial monolayers. ${ }^{150}$ In vivo evidence supporting that IgA transcytosis is required for viral inactivation was obtained when mice were only protected against rotavirus infection when IgA mAbs were given systemically, but not when they were provided via the lumen of the intestinal tract. ${ }^{151} \mathrm{~A}$ proinflammatory role for $\mathrm{dIgA}$ was recently proposed to eliminate pathogens that have successfully evaded the epithelial barrier. Bacteria, which are opsonized with dIgA, are efficiently phagocytosed by neutrophils. ${ }^{123}$ Moreover, interaction of dIgA with neutrophil Fc $\alpha$ RI leads to release of leukotrien B4, which is a potent neutrophil chemoattractant (Figure 3b). ${ }^{130}$ As such, it is hypothesized that a self-contained positive feedback loop is initiated, which results in enhanced recruitment of neutrophils, until clearance of invading pathogens has been achieved. Thus, $\operatorname{dIg} A$ functions as active second line of defense at mucosal surfaces by recruiting neutrophils.

The function of serum IgA in immunity is even more complicated and incompletely understood. It was demonstrated that IgA has the ability to downregulate IgG-mediated effector functions by transducing inhibitory signals through Fc $\alpha$ RI. ${ }^{133-139}$ However, Kupffer cells in the liver, which are essential for elimination of bacteria in the portal circulation that have invaded via the gut, were demonstrated to express Fc $\alpha \mathrm{RI} .{ }^{56} \mathrm{In}$ addition, serum IgA-opsonized Escherichia coli bacteria were efficiently phagocytosed by Kupffer cells, supporting a role for serum IgA in clearance of pathogens at the interface between 
mucosal and systemic immunity. Thus, crosslinking of Fc $\alpha$ RI on Kupffer cells by serum IgA functions as the third line of defense (Figure 3c).

The importance of FcaRI in mucosal infections was supported by two in vivo studies in human FcaRI transgenic mice, which express FcaRI on myeloid cells, similarly as in humans. ${ }^{103,152}$ When mice were infected with Bordetella pertussis that had been opsonized with human IgA, enhanced bacterial clearance in lungs of human Fc $\alpha$ RI transgenic mice was observed compared with non-transgenic littermates. ${ }^{124}$ Furthermore, it was recently shown that passive transfer of human IgA mAbs against Mycobacterium tuberculosis protected human Fc $\alpha$ RI transgenic mice, but not Fc $\alpha$ RI-negative control mice, against $M$. tuberculosis infection. ${ }^{153}$ To date, enhanced in vitro uptake of E. coli, Streptococcus pneumonia, Staphylococcus aureus, Porphyromonas gingivalis, Candida albicans, B. pertussis, and Neisseria meningitidis by neutrophils after targeting of Fc $\alpha$ RI have been demonstrated. ${ }^{56,123,124,130,154-156}$

\section{Fc $\alpha$ RI AS THERAPEUTIC TARGET}

Because Fc $\alpha$ RI has a dual role in immunity, as naturally occurring serum IgA induces inhibitory signals to dampen excessive immune responses, whereas crosslinking of Fc $\alpha$ RI during infection with IgA-opsonized pathogens results in proinflammatory responses; manipulation of Fc $\alpha$ RI function may offer novel promising therapeutic strategies. Until now, no (bispecific) $\mathrm{Ab}$ (BsAb)-based therapies that target Fc $\alpha$ RI exist in the clinic. Most of the research to investigate the potential of IgA mAbs for immunotherapeutical approaches has been based on in vitro experiments, but the increasing availability of suitable mouse models will greatly facilitate future in vivo studies. Two human Fc $\alpha$ RI transgenic mouse models are currently available, in which Fc $\alpha \mathrm{RI}$ is either expressed on monocytes/macrophages or preferentially on neutrophilic granulocytes. ${ }^{103,157}$ The complementary FcaRI expression in these models will allow studying the involvement of either cell type in disease or therapeutic efficacy.

Although it has been a challenge in the past to generate sufficient amounts of purified human IgA, technologies to reclone IgG mAbs, phage display, or transgenic plant technology has resulted in the generation of specific human IgA mAbs (as generation of sufficient BsAb is labor intensive with low yield, and as such may be unrealistic for clinical use). Moreover, the development of human IgA knock-in mouse model useable for standard hybridoma technology, ${ }^{158}$ and new approaches in IgA purification techniques ${ }^{159-161}$ will furthermore allow the production of a continuous source of antigen-specific human IgA.

\section{Fc $\alpha$ RI AS ANTI-INFLAMMATORY THERAPEUTIC TOOL}

Two experimental inflammatory disease models have been described that demonstrate the potential of dampening excessive immune responses (initiated by other Ig-immune complexes) by inducing ITAMi signaling (Figure $2 \mathbf{b}$ ) through Fc $\alpha$ RI. First, Fc $\alpha$ RI transgenic mice (expressing Fc $\alpha$ RI on monocytes/macrophages) that were immunized with IgE- immune complexes developed bronchial hyper-reactivity after challenge with the antigen. Treatment with anti-FcaRI Fab, which targets Fc $\alpha$ RI monovalently, hereby inducing ITAMi signaling-significantly reduced peribronchial inflammatory cell infiltration as well as symptoms. ${ }^{131}$ Second, both, decreased inflammatory cell infiltrates and fibrosis were observed in Fc $\alpha$ RI mice that were treated with anti-Fc $\alpha$ RI Fab in kidney inflammation models. ${ }^{162}$ Moreover, anti-FcaRI Fabs were shown to induce apoptosis in Fc $\alpha$ RI-expressing mast cell transfectants, which prevented tumor development and halted the growth of established tumors. ${ }^{163}$ As such, targeting ITAMi via FcaRI can initiate either inhibitory signals or apoptosis, which may help to control disproportionate inflammation or tumor development. The therapeutic potential of targeting ITAMi has recently been reviewed by Monteiro et al. ${ }^{141,164}$

\section{TARGETING FC $\alpha$ RI FOR TREATMENT OF INFECTIOUS DISEASES AND CANCER}

Because IgA is predominantly present in mucosal areas where it shows several important functions (see above), therapies that aim to increase specific IgA titers against mucosal pathogens may help to fight (mucosal) infection. For instance, treatment with specific IgA protected mice against rotavirus, which is a diarrhea-causing pathogen. ${ }^{151}$ Interestingly, protective effect was only observed when IgA mAbs were given systemically, but not when IgA was presented via the lumen of the intestinal tract. These results therefore not only support the hypothesis that IgA transcytosis is required for intracellular viral inactivation but also suggest that transport of systemically delivered $\operatorname{IgA}$ via the $\mathrm{pIgR}$ route is not hampered by locally produced mucosal IgA. ${ }^{151}$ Similarly, increased presence of mucosal IgA by either passive transfer with specific IgA or through oral immunization prevented Helicobacter felis, ${ }^{165}$ Helicobacter pylori, ${ }^{166}$ influenza, ${ }^{167,168}$ or Shigella flexneri ${ }^{169}$ infection. Importantly, as these experiments were performed in mice, which lack Fc $\alpha$ RI, the protective effect of IgA is presumably even more pronounced in humans. Mucosal administration of an HIV-1 vaccine resulted in resistance to the virus and production of virus-specific IgA with HIV-1 transcystosis-blocking properties in Macaca mulatta monkeys. ${ }^{170}$ However, it was recently demonstrated that targeting Fc $\alpha$ RI directed neutrophils to destroy HIV-infected target cells. ${ }^{171}$ Because M. mulatta monkeys express Fc $\alpha \mathrm{RI}$, an active role for Fc $\alpha \mathrm{RI}$ in eliciting protection is suggested, in addition to HIV neutralizing IgA Ab. Treatment of human Fc $\alpha$ RI transgenic mice with specific IgA induced enhanced protection against $B$. pertussis or $M$. tuberculosis infection, compared with non-transgenic littermates. ${ }^{124,153}$

Fc $\alpha$ RI was furthermore proposed as a novel trigger molecule for $\mathrm{mAb}$-based anti-cancer therapy. ${ }^{172,173}$ Although low expression of Fc $\alpha$ RI on DCs, poor ability of efficient Ag presentation, and no cross-presentation limits Fc $\alpha$ RI targeting on DCs for development of cancer vaccines, it was demonstrated that targeting Fc $\alpha$ RI efficiently recruits neutrophils as effector cells. In vitro experiments using therapeutic IgA1, IgA2, dIgA, chimeric IgA, or Fc $\alpha$ RI BsAb have provided promising results. ${ }^{127,128,172-186}$ For instance, neutrophils killed tumor cells much more effectively in 
the presence of anti-(HER2/neu $\times$ FcaRI) BsAb, or anti-EpCAM IgA mAbs compared with an IgG counterpart. Similar superior ability of Fc $\alpha$ RI to induce neutrophil-mediated tumor cell killing has now also been demonstrated for epidermal growth factor receptor, human leukocyte antigen class II, CD20, CD30, and carcinoembryonic antigen. ${ }^{127,172-174,176-186}$ One explanation for increased Ab-dependent-cellular cytotoxicity after targeting with IgA mAb or FcaRI BsAb may be the induction of neutrophil migration in the presence of IgA. Neutrophil accumulation and destruction of either mamma carcinoma or colon carcinoma colonies in a three-dimensional culture system was only observed when FcaRI was targeted, which is likely the result of leukotrien B4 release after crosslinking of Fc $\alpha$ RI. ${ }^{127,130,187}$ However, it was previously shown that immature bone marrow neutrophils were not capable of killing tumor cells via Fc $\gamma$ RI, whereas Fc $\alpha$ RI efficiently induced Ab-dependent-cellular cytotoxicity. ${ }^{128}$ It is therefore likely that the amplitude of signals mediated through $\mathrm{F} c \alpha \mathrm{RI}$ or Fc $\gamma \mathrm{R}$ also differs, as interaction of Fc $\alpha$ RI with FcR $\gamma$-chain is stronger because of an electrostatic interaction (Figure 2) that is absent for Fc $\gamma R .{ }^{102}$ An attractive feature of recruiting neutrophils as effector cells is the fact that targeting Fc $\alpha$ RI on neutrophils was recently demonstrated to induce autophagic tumor cell death (and necrosis to a lesser extend). ${ }^{188}$ As such, neutrophils may be able to kill tumor cells with mutations in apoptotic pathways. Moreover, neutrophils attract Th17 cells, which have been shown to have a role in anti-tumor immunity, ${ }^{189,190}$ and moreover secrete cytokines and chemokines that attract other immune cells (monocytes or DCs), which may result in more generalized anti-tumor immune responses. ${ }^{191}$

\section{CONCLUSION}

Fc $\alpha$ RI has a significant role in vivo for maintaining appropriate immune responses in both systemic and mucosal compartments. On one hand, FcaRI is involved in the prevention of superfluous immune responses that are initiated through other activating receptors. On the other hand, IgA can potently trigger protective immunity by crosslinking Fc $\alpha$ RI on myeloid immune cells. The lack of FcaRI expression in mice has previously seriously hampered in vivo experiments to further elucidate the involvement of Fc $\alpha$ RI in anti- and proinflammatory functions. Currently increasing availability of suitable genetically engineered mouse models will significantly facilitate future in vivo studies to establish the complex role of FcaRI in (mucosal) immunity and its potential as therapeutic target for human diseases.

\section{ACKNOWLEDGMENTS}

J.E Bakema and M. van Egmond are supported by the Maag Lever Darm stichting (WO 10-41) and by the Netherlands Organization for Scientific Research (VIDI 016.086.320).

\section{DISCLOSURE}

The authors declared no conflict of interest.

() 2011 Society for Mucosal Immunology

\section{REFERENCES}

1. Fagarasan, S. \& Honjo, T. Intestinal IgA synthesis: regulation of front-line body defences. Nat. Rev. Immuno/ 3, 63-72 (2003).
2. Pamer, E.G. Immune responses to commensal and environmental microbes. Nat. Immunol. 8, 1173-1178 (2007).

3. Macpherson, A.J. et al. A primitive T cell-independent mechanism of intestinal mucosal IgA responses to commensal bacteria. Science $\mathbf{2 8 8}$, 2222-2226 (2000).

4. Woof, J.M. \& Kerr, M.A. The function of immunoglobulin A in immunity. J. Pathol. 208, 270-282 (2006).

5. Johansen, F.E., Braathen, R. \& Brandtzaeg, P. The J chain is essential for polymeric Ig receptor-mediated epithelial transport of IgA. J. Immunol. 167, 5185-5192 (2001).

6. Braathen, R., Sorensen, V., Brandtzaeg, P., Sandlie, I. \& Johansen, F.E. The carboxyl-terminal domains of IgA and IgM direct isotype-specific polymerization and interaction with the polymeric immunoglobulin receptor. J. Biol. Chem 277, 42755-42762 (2002).

7. Lewis, M.J., Pleass, R.J., Batten, M.R., Atkin, J.D. \& Woof, J.M. Structural requirements for the interaction of human IgA with the human polymeric Ig receptor. J. Immunol. 175, 6694-6701 (2005).

8. Mostov, K.E. Transepithelial transport of immunoglobulins. Annu. Rev. Immunol. 12, 63-84 (1994).

9. Shibuya, A. et al. Fc alpha/mu receptor mediates endocytosis of IgM-coated microbes. Nat. Immunol. 1, 441-446 (2000).

10. Stockert, R.J., Kressner, M.S., Collins, J.C., Sternlieb, I. \& Morell, A.G. IgA interaction with the asialoglycoprotein receptor. Proc. Natl Acad. Sci. USA 79, 6229-6231 (1982).

11. Moura, I.C. et al. Identification of the transferrin receptor as a novel immunoglobulin (Ig)A1 receptor and its enhanced expression on mesangial cells in IgA nephropathy. J. Exp. Med. 194, 417-425 (2001).

12. Lamkhioued, B. et al. Human eosinophils express a receptor for secretory component. Role in secretory lgA-dependent activation. Eur. J. Immunol. 25, 117-125 (1995).

13. Mantis, N.J. et al. Selective adherence of IgA to murine Peyer's patch $M$ cells: evidence for a novel IgA receptor. J. Immunol. 169, 1844-1851 (2002).

14. Reljic, R. In search of the elusive mouse macrophage Fc-alpha receptor. Immunol. Lett. 107, 80-81 (2006).

15. Woof, J.M. \& Kerr, M.A. IgA function-variations on a theme. Immunology 113, 175-177 (2004).

16. Maruoka, T., Nagata, T. \& Kasahara, M. Identification of the rat IgA FC receptor encoded in the leukocyte receptor complex. Immunogenetics 55, 712-716 (2004).

17. Morton, H.C. et al. Cloning and characterization of an immunoglobulin $A$ Fc receptor from cattle. Immunology 111, 204-211 (2004).

18. Morton, H.C., Pleass, R.J., Storset, A.K., Brandtzaeg, P. \& Woof, J.M. Cloning and characterization of equine CD89 and identification of the CD89 gene in chimpanzees and Rhesus macaques. Immunology 115 , 74-84 (2005).

19. Morton, H.C. IgA Fc receptors in cattle and horses. Vet. Immunol. Immunopathol. 108, 139-143 (2005).

20. Kazeeva, T.N. \& Shevelev, A.B. IgA-specific proteins of pathogenic bacteria. Biochemistry (Mosc) 74, 12-21 (2009).

21. Kremer, E.J. et al. The gene for the human IgA Fc receptor maps to 19q13.4. Hum. Genet. 89, 107-108 (1992).

22. Martin, A.M., Kulski, J.K., Witt, C., Pontarotti, P. \& Christiansen, F.T. Leukocyte lg-like receptor complex (LRC) in mice and men. Trends Immunol. 23, 81-88 (2002).

23. Daeron, M. Fc receptor biology. Annu. Rev. Immunol. 15, 203-234 (1997).

24. Nimmerjahn, F. \& Ravetch, J.V. Fc gamma receptors: old friends and new family members. Immunity 24, 19-28 (2006).

25. Monteiro, R.C. \& Van De Winkel, J.G. IgA Fc receptors. Annu. Rev. Immunol. 21, 177-204 (2003).

26. Ono, M., Yuasa, T., Ra, C. \& Takai, T. Stimulatory function of paired immunoglobulin-like receptor-A in mast cell line by associating with subunits common to Fc receptors. J. Biol. Chem. 274, 30288-30296 (1999).

27. Maliszewski, C.R., March, C.J., Schoenborn, M.A., Gimpel, S. \& Shen, L. Expression cloning of a human Fc receptor for IgA. J. Exp. Med. 172, 1665-1672 (1990).

28. de Wit, T.P., Morton, H.C., Capel, P.J. \& van de Winkel, J.G. Structure of the gene for the human myeloid IgA Fc receptor (CD89). J. Immunol. 155, 1203-1209 (1995).

29. Morton, H.C., van Egmond, M. \& van de Winkel, J.G. Structure and function of human IgA Fc receptors (Fc alpha R). Crit. Rev. Immunol. 16, 423-440 (1996). 
30. Toyabe, S., Kuwano, Y., Takeda, K., Uchiyama, M. \& Abo, T. IgA nephropathy-specific expression of the IgA Fc receptors (CD89) on blood phagocytic cells. Clin. Exp. Immunol. 110, 226-232 (1997).

31. Shimokawa, T., Tsuge, T., Okumura, K. \& Ra, C. Identification and characterization of the promoter for the gene encoding the human myeloid IgA Fc receptor (Fc alphaR, CD89). Immunogenetics 51, 945-954 (2000).

32. Shimokawa, T. \& Ra, C. C/EBP alpha and Ets protein family members regulate the human myeloid IgA Fc receptor (Fc alpha R, CD89) promoter. J. Immunol. 170, 2564-2572 (2003).

33. Shimokawa, T. \& Ra, C. C/EBPalpha functionally and physically interacts with GABP to activate the human myeloid IgA Fc receptor ( $F$ c alphaR, CD89) gene promoter. Blood 106, 2534-2542 (2005).

34. Monteiro, R.C., Kubagawa, H. \& Cooper, M.D. Cellular distribution, regulation, and biochemical nature of an Fc alpha receptor in humans. J. Exp. Med. 171, 597-613 (1990).

35. Monteiro, R.C., Cooper, M.D. \& Kubagawa, H. Molecular heterogeneity of Fc alpha receptors detected by receptor-specific monoclonal antibodies. J. Immunol. 148, 1764-1770 (1992).

36. Monteiro, R.C. et al. Definition of immunoglobulin A receptors on eosinophils and their enhanced expression in allergic individuals. J. Clin. Invest. 92, 1681-1685 (1993).

37. Patry, C., Sibille, Y., Lehuen, A. \& Monteiro, R.C. Identification of FC alpha receptor (CD89) isoforms generated by alternative splicing that are differentially expressed between blood monocytes and alveolar macrophages. J. Immunol. 156, 4442-4448 (1996).

38. van Dijk, T.B. et al. Cloning and characterization of Fc alpha Rb, a novel Fc alpha receptor (CD89) isoform expressed in eosinophils and neutrophils. Blood 88, 4229-4238 (1996).

39. van Zandbergen, G. et al. Crosslinking of the human Fc receptor for IgA (Fc alphaRI/CD89) triggers FcR gamma-chain-dependent shedding of soluble CD89. J. Immunol. 163, 5806-5812 (1999).

40. Yin, N., Peng, M., Xing, Y. \& Zhang, W. Intracellular pools of Fc alphaR (CD89) in human neutrophils are localized in tertiary granules and secretory vesicles, and two Fc alphaR isoforms are found in tertiary granules. J. Leukoc. Biol. 82, 551-558 (2007).

41. Pleass, R.J., Andrews, P.D., Kerr, M.A. \& Woof, J.M. Alternative splicing of the human IgA Fc receptor CD89 in neutrophils and eosinophils. Biochem. J. 318 (Pt 3), 771-777 (1996).

42. Togo, S., Shimokawa, T., Fukuchi, Y. \& Ra, C. Alternative splicing of myeloid IgA Fc receptor (Fc alpha R, CD89) transcripts in inflammatory responses. FEBS Lett. 535, 205-209 (2003).

43. Reterink, T.J., Verweij, C.L., van Es, L.A. \& Daha, M.R. Alternative splicing of IgA Fc receptor (CD89) transcripts. Gene 175, 279-280 (1996).

44. Pleass, R.J., Dunlop, J.I. \& Woof, J.M. Multiple transcripts of human IgA Fc receptor CD89 in neutrophils, eosinophils and the monocyte-like cell line THP-1. Biochem. Soc. Trans. 25, 327S (1997).

45. van Vuuren, A.J., van Egmond, M., Coenen, M.J., Morton, H.C. \& van de Winkel, J.G. Characterization of the human myeloid IgA Fc receptor I (CD89) gene in a cosmid clone. Immunogenetics 49, 586-589 (1999).

46. Tsuge, T., Shimokawa, T., Horikoshi, S., Tomino, Y. \& Ra, C. Polymorphism in promoter region of $\mathrm{Fc}$ alpha receptor gene in patients with IgA nephropathy. Hum. Genet. 108, 128-133 (2001).

47. Jasek, M. et al. A novel polymorphism in the cytoplasmic region of the human immunoglobulin A Fc receptor gene. Eur. J. Immunogenet. 31, 59-62 (2004).

48. Kaneko, S. et al. A novel polymorphism of FC alphaRI (CD89) associated with aggressive periodontitis. Tissue Antigens 63, 572-577 (2004).

49. Watanabe, A. et al. Genetic variants of the IgA Fc receptor ( $F_{C}$ alphaR, CD89) promoter in chronic hepatitis $\mathrm{C}$ patients. Immunogenetics $\mathbf{5 8 ,}$ 937-946 (2006).

50. Wu, J. et al. Fc alphaRI (CD89) alleles determine the proinflammatory potential of serum IgA. J. Immunol. 178, 3973-3982 (2007).

51. Bournazos, S., Woof, J.M., Hart, S.P. \& Dransfield, I. Functional and clinical consequences of Fc receptor polymorphic and copy number variants. Clin. Exp. Immunol. 157, 244-254 (2009).

52. Jasek, M. et al. Are single nucleotide polymorphisms of the immunoglobulin A Fc receptor gene associated with allergic asthma? Int. Arch. Allergy Immunol. 135, 325-331 (2004).

53. Broen, J.C. et al. The functional polymorphism $844 \mathrm{~A}>\mathrm{G}$ in FC alphaRI (CD89) does not contribute to systemic sclerosis or rheumatoid arthritis susceptibility. J. Rheumatol. 38, 446-449.
54. Narita, I. et al. Genetic polymorphisms in the promoter and 5' UTR region of the Fc alpha receptor (CD89) are not associated with a risk of IgA nephropathy. J. Hum. Genet. 46, 694-698 (2001).

55. Sibille, Y., Chatelain, B., Staquet, P., Delacroix, D.L. \& Vaerman, J.P. IgA receptors on human alveolar macrophages. Monogr. Allergy 24, 282-286 (1988).

56. van Egmond, M. et al. Fc alphaRI-positive liver Kupffer cells: reappraisal of the function of immunoglobulin A in immunity. Nat. Med. 6, 680-685 (2000).

57. Geissmann, F. et al. A subset of human dendritic cells expresses IgA FC receptor (CD89), which mediates internalization and activation upon cross-linking by IgA complexes. J. Immunol. 166, 346-352 (2001).

58. Smith, P.D. et al. Intestinal macrophages lack CD14 and CD89 and consequently are down-regulated for LPS- and IgA-mediated activities. J. Immunol. 167, 2651-2656 (2001).

59. Heystek, H.C., Moulon, C., Woltman, A.M., Garonne, P. \& van Kooten, C. Human immature dendritic cells efficiently bind and take up secretory IgA without the induction of maturation. J. Immunol. 168, 102-107 (2002).

60. Qian, K. et al. Functional expression of IgA receptor Fc alphaRI on human platelets. J. Leukoc. Biol. 84, 1492-1500 (2008).

61. Chevailler, A., Monteiro, R.C., Kubagawa, H. \& Cooper, M.D. Immunofluorescence analysis of IgA binding by human mononuclear cells in blood and lymphoid tissue. J. Immunol. 142, 2244-2249 (1989).

62. Bakema, J.E. et al. C-Jun activating binding protein 1 binds to the IgA receptor and modulates protein levels of $\mathrm{FC}$ alphaRI and FCR gammachain. Eur. J. Immunol. 40, 2035-2040 (2010).

63. Shen, L., Collins, J.E., Schoenborn, M.A. \& Maliszewski, C.R. Lipopolysaccharide and cytokine augmentation of human monocyte IgA receptor expression and function. J. Immunol. 152, 4080-4086 (1994).

64. Gessl, A. et al. Influence of tumour necrosis factor-alpha on the expression of $\mathrm{Fc} \lg \mathrm{G}$ and $\mathrm{IgA}$ receptors, and other markers by cultured human blood monocytes and U937 cells. Scand. J. Immunol. 39, 151-156 (1994).

65. Hostoffer, R.W., Krukovets, I. \& Berger, M. Increased Fc alpha R expression and IgA-mediated function on neutrophils induced by chemoattractants. J. Immunol. 150, 4532-4540 (1993).

66. Hostoffer, R.W., Krukovets, I. \& Berger, M. Enhancement by tumor necrosis factor-alpha of Fc alpha receptor expression and IgA-mediated superoxide generation and killing of Pseudomonas aeruginosa by polymorphonuclear leukocytes. J. Infect. Dis. 170, 82-87 (1994).

67. Reterink, T.J., Levarht, E.W., Klar-Mohamad, N., Van Es, L.A. \& Daha, M.R. Transforming growth factor-beta 1 (TGF-beta 1) down-regulates IgA Fc-receptor (CD89) expression on human monocytes. Clin. Exp. Immunol. 103, 161-166 (1996).

68. Grossetete, B. et al. Down-regulation of Fc alpha receptors on blood cells of IgA nephropathy patients: evidence for a negative regulatory role of serum IgA. Kidney Int. 53, 1321-1335 (1998).

69. Hamre, R., Farstad, I.N., Brandtzaeg, P. \& Morton, H.C. Expression and modulation of the human immunoglobulin A Fc receptor (CD89) and the FcR gamma chain on myeloid cells in blood and tissue. Scand. J. Immunol. 57, 506-516 (2003).

70. Grossetete, B., Viard, J.P., Lehuen, A., Bach, J.F. \& Monteiro, R.C. Impaired Fc alpha receptor expression is linked to increased immunoglobulin A levels and disease progression in HIV-1-infected patients. AIDS 9, 229-234 (1995).

71. Chiamolera, M. et al. Enhanced expression of Fc alpha receptor I on blood phagocytes of patients with gram-negative bacteremia is associated with tyrosine phosphorylation of the FCR-gamma subunit. Shock 16, 344-348 (2001).

72. Montenegro, V., Chiamolera, M., Launay, P., Goncalves, C.R. \& Monteiro, R.C. Impaired expression of IgA Fc receptors (CD89) by blood phagocytic cells in ankylosing spondylitis. J. Rheumatol. 27, 411-417 (2000).

73. Wines, B.D. et al. Identification of residues in the first domain of human Fc alpha receptor essential for interaction with IgA. J. Immunol. 162, 2146-2153 (1999).

74. Wines, B.D., Sardjono, C.T., Trist, H.H., Lay, C.S. \& Hogarth, P.M. The interaction of $F_{C}$ alpha RI with IgA and its implications for ligand binding by immunoreceptors of the leukocyte receptor cluster. J. Immunol. 166, 1781-1789 (2001). 
75. Herr, A.B., Ballister, E.R. \& Bjorkman, P.J. Insights into IgA-mediated immune responses from the crystal structures of human FcalphaRI and its complex with IgA1-Fc. Nature 423, 614-620 (2003).

76. Ding, Y. et al. Crystal structure of the ectodomain of human Fc alphaRl. J. Biol. Chem. 278, 27966-27970 (2003).

77. Oortwijn, B.D. et al. Monomeric and polymeric IgA show a similar association with the myeloid Fc alphaRI/CD89. Mol. Immunol. 44, 966-973 (2007).

78. van Spriel, A.B. et al. Mac-1 (CD11b/CD18) is essential for Fc receptormediated neutrophil cytotoxicity and immunologic synapse formation. Blood 97, 2478-2486 (2001).

79. Woof, J.M. \& Burton, D.R. Human antibody-Fc receptor interactions illuminated by crystal structures. Nat. Rev. Immunol. 4, 89-99 (2004).

80. Bonner, A., Almogren, A., Furtado, P.B., Kerr, M.A. \& Perkins, S.J. Location of secretory component on the Fc edge of dimeric IgA1 reveals insight into the role of secretory lgA1 in mucosal immunity. Mucosal. Immunol. 2, 74-84 (2009).

81. Shi, J. et al. Interaction of the low-affinity receptor CD23/Fc epsilon RII lectin domain with the Fc epsilon3-4 fragment of human immunoglobulin E. Biochemistry 36, 2112-2122 (1997).

82. Keown, M.B., Ghirlando, R., Mackay, G.A., Sutton, B.J. \& Gould, H.J. Basis of the 1:1 stoichiometry of the high affinity receptor Fc epsilon RI-lgE complex. Eur. Biophys. J. 25, 471-476 (1997).

83. Sondermann, P., Huber, R., Oosthuizen, V. \& Jacob, U. The 3.2-A crystal structure of the human IgG1 Fc fragment-Fc gammaRIII complex. Nature 406, 267-273 (2000).

84. Keown, M.B., Henry, A.J., Ghirlando, R., Sutton, B.J. \& Gould, H.J. Thermodynamics of the interaction of human immunoglobulin $E$ with its high-affinity receptor Fc epsilon RI. Biochemistry 37, 8863-8869 (1998).

85. Zhang, Y. et al. Crystal structure of the extracellular domain of a human FC gamma RIII. Immunity 13, 387-395 (2000).

86. Pleass, R.J., Dunlop, J.I., Anderson, C.M. \& Woof, J.M. Identification of residues in the $\mathrm{CH} 2 / \mathrm{CH} 3$ domain interface of IgA essential for interaction with the human Fc alpha receptor (Fc alphaR) CD89. J. Biol. Chem. 274, 23508-23514 (1999).

87. Reterink, T.J. et al. Size-dependent effect of IgA on the IgA Fc receptor (CD89). Eur. J. Immunol. 27, 2219-2224 (1997).

88. Xue, J., Zhao, Q., Zhu, L. \& Zhang, W. Deglycosylation of Fc alphaR at N58 increases its binding to lgA. Glycobiology 20, 905-915 (2010).

89. Gomes, M.M. et al. Analysis of lgA1 N-glycosylation and its contribution to FC alphaRI binding. Biochemistry 47, 11285-11299 (2008).

90. Mattu, T.S. et al. The glycosylation and structure of human serum lgA1, $\mathrm{Fab}$, and $\mathrm{Fc}$ regions and the role of $\mathrm{N}$-glycosylation on $\mathrm{Fc}$ alpha receptor interactions. J. Biol. Chem. 273, 2260-2272 (1998).

91. Shen, L., Lasser, R. \& Fanger, M.W. My 43, a monoclonal antibody that reacts with human myeloid cells inhibits monocyte lgA binding and triggers function. J. Immunol. 143, 4117-4122 (1989).

92. Morton, H.C. et al. Immunoglobulin-binding sites of human Fc alphaRI (CD89) and bovine Fc gamma2R are located in their membrane-distal extracellular domains. J. Exp. Med. 189, 1715-1722 (1999).

93. Lu, J. et al. Recognition and functional activation of the human IgA receptor (Fc\{alpha\}RI) by C-reactive protein. Proc. Natl Acad. Sci. USA 108, 4974-4979 (2011).

94. Weisbart, R.H., Kacena, A., Schuh, A. \& Golde, D.W. GM-CSF induces human neutrophil IgA-mediated phagocytosis by an IgA Fc receptor activation mechanism. Nature 332, 647-648 (1988).

95. Baldwin, G.C. et al. Granulocyte-macrophage colony-stimulating factor enhances neutrophil function in acquired immunodeficiency syndrome patients. Proc. Natl Acad. Sci. USA 85, 2763-2766 (1988).

96. Bracke, M. et al. Differential effects of the T helper cell type 2-derived cytokines IL-4 and IL-5 on ligand binding to IgG and IgA receptors expressed by human eosinophils. J. Immunol. 159, 1459-1465 (1997).

97. Bracke, M., Lammers, J.W., Coffer, P.J. \& Koenderman, L. Cytokineinduced inside-out activation of Fc alphaR (CD89) is mediated by a single serine residue (S263) in the intracellular domain of the receptor. Blood 97, 3478-3483 (2001).

98. Bakema, J.E. et al. Inside-out regulation of Fc alpha RI (CD89) depends on PP2A. J. Immunol. 181, 4080-4088 (2008).

99. Ginsberg, M.H., Partridge, A. \& Shattil, S.J. Integrin regulation. Curr. Opin. Cell Biol. 17, 509-516 (2005).

100. Smith, A.D., Streilein, R.D. \& Hall, R.P. III Neutrophil CD11b, L-selectin and FC IgA receptors in patients with dermatitis herpetiformis. Br. J. Dermatol. 147, 1109-1117 (2002).
101. Pfefferkorn, L.C. \& Yeaman, G.R. Association of IgA-Fc receptors (Fc alpha R) with Fc epsilon RI gamma 2 subunits in U937 cells. Aggregation induces the tyrosine phosphorylation of gamma 2. J. Immunol. 153, 3228-3236 (1994).

102. Morton, H.C. et al. Functional association between the human myeloid immunoglobulin A Fc receptor (CD89) and FCR gamma chain. Molecular basis for CD89/FcR gamma chain association. J. Biol. Chem. 270, 29781-29787 (1995).

103. van Egmond, M. et al. Human immunoglobulin A receptor (Fc alphaRI, CD89) function in transgenic mice requires both FCR gamma chain and CR3 (CD11b/CD18). Blood 93, 4387-4394 (1999).

104. Bakema, J.E. et al. Signaling through mutants of the IgA receptor CD89 and consequences for Fc receptor gamma-chain interaction. J. Immunol. 176, 3603-3610 (2006).

105. Wines, B.D., Trist, H.M., Monteiro, R.C., Van Kooten, C. \& Hogarth, P.M. Fc receptor gamma chain residues at the interface of the cytoplasmic and transmembrane domains affect association with $\mathrm{Fc}$ alphaRI, surface expression, and function. J. Biol. Chem. 279, 26339-26345 (2004).

106. Wines, B.D., Trist, H.M., Ramsland, P.A. \& Hogarth, P.M. A common site of the Fc receptor gamma subunit interacts with the unrelated immunoreceptors Fc alphaRI and Fc epsilonRI. J. Biol. Chem. 281, 17108-17113 (2006).

107. Launay, P. et al. Alternative endocytic pathway for immunoglobulin A Fc receptors (CD89) depends on the lack of FCRgamma association and protects against degradation of bound ligand. J. Biol. Chem. 274, 7216-7225 (1999).

108. Honorio-Franca, A.C., Launay,p P., Carneiro-Sampaio, M.M. \& Monteiro, R.C. Colostral neutrophils express Fc alpha receptors (CD89) lacking gamma chain association and mediate noninflammatory properties of secretory IgA. J. Leukoc. Biol. 69, 289-296 (2001).

109. Shen, L. et al. Presentation of ovalbumin internalized via the immunoglobulin-A Fc receptor is enhanced through Fc receptor gamma-chain signaling. Blood 97, 205-213 (2001).

110. Lanier, L.L., Corliss, B.C., Wu, J., Leong, C. \& Phillips, J.H. Immunoreceptor DAP12 bearing a tyrosine-based activation motif is involved in activating NK cells. Nature 391, 703-707 (1998).

111. Westgaard, I.H. et al. Rat NKp46 activates natural killer cell cytotoxicity and is associated with Fc epsilon RI gamma and CD3zeta. J. Leukoc. Biol. 76, 1200-1206 (2004).

112. Kim, M.K. et al. Fc gamma receptor transmembrane domains: role in cell surface expression, gamma chain interaction, and phagocytosis. Blood 101, 4479-4484 (2003).

113. Ravetch, J.V. \& Kinet, J.P. Fc receptors. Annu. Rev. Immunol. 9, 457-492 (1991)

114. Kinet, J.P. The high-affinity receptor for IgE. Curr. Opin. Immunol. 2, 499-505 (1989).

115. Lang, M.L., Shen, L. \& Wade, W.F. Gamma-chain dependent recruitment of tyrosine kinases to membrane rafts by the human IgA receptor Fc alpha R. J. Immunol. 163, 5391-5398 (1999).

116. Gulle, H., Samstag, A., Eibl, M.M. \& Wolf, H.M. Physical and functional association of Fc alpha $\mathrm{R}$ with protein tyrosine kinase Lyn. Blood 91, 383-391 (1998).

117. Launay, P., Lehuen, A., Kawakami, T., Blank, U. \& Monteiro, R.C. IgA Fc receptor (CD89) activation enables coupling to syk and Btk tyrosine kinase pathways: differential signaling after IFN-gamma or phorbol ester stimulation. J. Leukoc. Biol. 63, 636-642 (1998).

118. Shen, L., Lang, M.L. \& Wade, W.F. The ins and outs of getting in: structures and signals that enhance BCR or Fc receptor-mediated antigen presentation. Immunopharmacology 49, 227-240 (2000).

119. Lang, M.L. et al. Fc alpha receptor cross-linking causes translocation of phosphatidylinositol-dependent protein kinase 1 and protein kinase B alpha to MHC class II peptide-loading-like compartments. J. Immunol. 166, 5585-5593 (2001).

120. Chen, Y.W., Lang, M.L. \& Wade, W.F. Protein kinase C-alpha and-delta are required for $\mathrm{FC}$ alphaR (CD89) trafficking to $\mathrm{MHC}$ class II compartments and Fc alphaR-mediated antigen presentation. Traffic 5, 577-594 (2004).

121. Park, R.K., Izadi, K.D., Deo, Y.M. \& Durden, D.L. Role of Src in the modulation of multiple adaptor proteins in FC alphaRI oxidant signaling. Blood 94, 2112-2120 (1999).

122. Lang, M.L. \& Kerr, M.A. Characterization of FC alphaR-triggered $\mathrm{Ca}(2+)$ signals: role in neutrophil NADPH oxidase activation. Biochem. Biophys. Res. Commun. 276, 749-755 (2000). 
123. Vidarsson, G. et al. Activity of human IgG and lgA subclasses in immune defense against Neisseria meningitidis serogroup B. J. Immunol. 166, 6250-6256 (2001).

124. Hellwig, S.M., van Spriel, A.B., Schellekens, J.F., Mooi, F.R. \& van de Winkel, J.G. Immunoglobulin A-mediated protection against Bordetella pertussis infection. Infect. Immun. 69, 4846-4850 (2001).

125. Ouadrhiri, Y., Pilette, C., Monteiro, R.C., Vaerman, J.P. \& Sibille, Y. Effect of IgA on respiratory burst and cytokine release by human alveolar macrophages: role of ERK1/2 mitogen-activated protein kinases and NF-kappaB. Am. J. Respir. Cell Mol. Biol. 26, 315-332 (2002).

126. Pilette, C., Detry, B., Guisset, A., Gabriels, J. \& Sibille, Y. Induction of interleukin-10 expression through Fc alpha receptor in human monocytes and monocyte-derived dendritic cells: role of p38 MAPKinase. Immunol. Cell Biol. 88, 486-493.

127. Otten, M.A. et al. Immature neutrophils mediate tumor cell killing via IgA but not IgG Fc receptors. J. Immunol. 174, 5472-5480 (2005).

128. Otten, M.A. et al. FcR gamma-chain dependent signaling in immature neutrophils is mediated by Fc alphaRI, but not by Fc gammaRl. J. Immunol. 179, 2918-2924 (2007).

129. Pleass, R.J., Lang, M.L., Kerr, M.A. \& Woof, J.M. IgA is a more potent inducer of NADPH oxidase activation and degranulation in blood eosinophils than IgE. Mol. Immunol. 44, 1401-1408 (2007).

130. van der Steen, L. et al. Immunoglobulin A: Fc(alpha)Rl interactions induce neutrophil migration through release of leukotriene B4. Gastroenterology 137, 2018-2029 e2011-2013 (2009).

131. Pasquier, B. et al. Identification of $\mathrm{FC}_{\mathrm{C}}$ alphaRI as an inhibitory receptor that controls inflammation: dual role of FCR gamma ITAM. Immunity 22, 31-42 (2005)

132. Kanamaru, Y., Blank, U. \& Monteiro, R.C. IgA Fc receptor I is a molecular switch that determines $\lg A$ activating or inhibitory functions. Contrib. Nephrol. 157, 148-152 (2007).

133. Van Epps, D.E. \& Brown, S.L. Inhibition of formylmethionyl-leucylphenylalanine-stimulated neutrophil chemiluminescence by human immunoglobulin A paraproteins. Infect. Immun. 34, 864-870 (1981).

134. Van Epps, D.E. \& Williams, R.C., Jr. Suppression of leukocyte chemotaxis by human IgA myeloma components. J. Exp. Med. 144, 1227-1242 (1976).

135. Van Epps, D.E., Reed, K. \& Williams, R.C., Jr. Suppression of human PMN bactericidal activity by human IgA paraproteins. Cell Immunol. 36, 363-376 (1978).

136. Wilton, J.M. Suppression by IgA of IgG-mediated phagocytosis by human polymorphonuclear leucocytes. Clin. Exp. Immunol. 34, 423-428 (1978).

137. Wolf, H.M. et al. Human serum IgA downregulates the release of inflammatory cytokines (tumor necrosis factor-alpha, interleukin-6) in human monocytes. Blood 83, 1278-1288 (1994).

138. Wolf, H.M. \& Eibl, M.M. The anti-inflammatory effect of an oral immunoglobulin (IgA-lgG) preparation and its possible relevance for the prevention of necrotizing enterocolitis. Acta. Paediatr. Suppl. 396, 37-40 (1994).

139. Nikolova, E.B. \& Russell, M.W. Dual function of human IgA antibodies: inhibition of phagocytosis in circulating neutrophils and enhancement of responses in IL-8-stimulated cells. J. Leukoc. Biol. 57, 875-882 (1995).

140. Pfirsch-Maisonnas, S. et al. Inhibitory ITAM signaling traps activating receptors with the phosphatase SHP-1 to form polarized "inhibisome" clusters. Sci. Signal. 4, ra24 (2011).

141. Blank, U., Launay, P., Benhamou, M. \& Monteiro, R.C. Inhibitory ITAMs as novel regulators of immunity. Immunol. Rev. 232, 59-71 (2009).

142. Pasquier, B., Lepelletier, Y., Baude, C., Hermine, O. \& Monteiro, R.C. Differential expression and function of IgA receptors (CD89 and CD71) during maturation of dendritic cells. J. Leukoc. Biol. 76, 1134-1141 (2004).

143. Fayette, J. et al. Human dendritic cells skew isotype switching of CD40activated naive B cells towards IgA1 and IgA2. J. Exp. Med. 185, 1909-1918 (1997)

144. Otten, M.A., Groenveld, I., van de Winkel, J.G. \& van Egmond, M. Inefficient antigen presentation via the IgA Fc receptor (Fc alphaRI) on dendritic cells. Immunobiology 211, 503-510 (2006).

145. Mazanec, M.B., Kaetzel, C.S., Lamm, M.E., Fletcher, D. \& Nedrud, J.G. Intracellular neutralization of virus by immunoglobulin A antibodies. Proc. Natl Acad. Sci. USA 89, 6901-6905 (1992).

146. Mazanec, M.B., Coudret, C.L. \& Fletcher, D.R. Intracellular neutralization of influenza virus by immunoglobulin $A$ anti-hemagglutinin monoclonal antibodies. J. Virol. 69, 1339-1343 (1995).
147. Mazanec, M.B. et al. Intracellular neutralization of Sendai and influenza viruses by IgA monoclonal antibodies. Adv. Exp. Med. Biol. 371A, 651-654 (1995).

148. Devito, C. et al. Mucosal and plasma IgA from HIV-1-exposed uninfected individuals inhibit HIV-1 transcytosis across human epithelial cells. J. Immunol. 165, 5170-5176 (2000).

149. Corthesy, B. et al. Rotavirus anti-VP6 secretory immunoglobulin A contributes to protection via intracellular neutralization but not via immune exclusion. J. Virol. 80, 10692-10699 (2006).

150. Stubbe, H., Berdoz, J., Kraehenbuhl, J.P. \& Corthesy, B. Polymeric IgA is superior to monomeric $\lg A$ and $\lg G$ carrying the same variable domain in preventing Clostridium difficile toxin A damaging of T84 monolayers. J. Immunol. 164, 1952-1960 (2000).

151. Burns, J.W., Siadat-Pajouh, M., Krishnaney, A.A. \& Greenberg, H.B. Protective effect of rotavirus VP6-specific IgA monoclonal antibodies that lack neutralizing activity. Science 272, 104-107 (1996).

152. van Egmond, M., Hanneke van Vuuren, A.J. \& van de Winkel, J.G. The human $F_{C}$ receptor for IgA (Fc alpha RI, CD89) on transgenic peritoneal macrophages triggers phagocytosis and tumor cell lysis. Immunol. Lett. 68, 83-87 (1999).

153. Balu, S. et al. A novel human IgA monoclonal antibody protects against tuberculosis. J. Immunol. 186, 3113-3119 (2011).

154. van Spriel, A.B. et al. Effective phagocytosis and killing of Candida albicans via targeting Fc gammaRI (CD64) or Fc alphaRI (CD89) on neutrophils. J. Infect. Dis. 179, 661-669 (1999).

155. van der Pol, W., Vidarsson, G., Vile, H.A., van de Winkel, J.G. \& Rodriguez, M.E. Pneumococcal capsular polysaccharide-specific IgA triggers efficient neutrophil effector functions via Fc alphaRI (CD89). J. Infect. Dis. 182, 1139-1145 (2000).

156. Kobayashi, T. et al. Effective in vitro clearance of Porphyromonas gingivalis by Fc alpha receptor I (CD89) on gingival crevicular neutrophils. Infect. Immun. 69, 2935-2942 (2001).

157. Launay, P. et al. Fcalpha receptor (CD89) mediates the development of immunoglobulin A (IgA) nephropathy (Berger's disease). Evidence for pathogenic soluble receptor-lga complexes in patients and CD89 transgenic mice. J. Exp. Med. 191, 1999-2009 (2000).

158. Duchez, S. et al. Premature replacement of mu with alpha immunoglobulin chains impairs lymphopoiesis and mucosal homing but promotes plasma cell maturation. Proc. Natl Acad. Sci. USA 107, 3064-3069 (2010).

159. Leibl, H., Tomasits, R. \& Mannhalter, J.W. Isolation of human serum IgA using thiophilic adsorption chromatography. Protein Expr. Purif. 6, 408-410 (1995).

160. Sandin, C. et al. Isolation and detection of human IgA using a streptococcal IgA-binding peptide. J. Immunol. 169, 1357-1364 (2002).

161. Beyer, T. et al. Serum-free production and purification of chimeric IgA antibodies. J. Immunol. Methods 346, 26-37 (2009).

162. Kanamaru, Y. et al. Inhibitory ITAM signaling by Fc alpha RI-FcR gamma chain controls multiple activating responses and prevents renal inflammation. J. Immunol. 180, 2669-2678 (2008).

163. Kanamaru, Y. et al. IgA Fc receptor I signals apoptosis through the FcR gamma ITAM and affects tumor growth. Blood 109, 203-211 (2007).

164. Monteiro, R.C. The role of IgA and IgA Fc receptors as anti-inflammatory agents. J. Clin. Immunol. 30 (Suppl 1), S61-64 (2010).

165. Blanchard, T.G. et al. Urease-specific monoclonal antibodies prevent Helicobacter felis infection in mice. Infect. Immun. 63, 1394-1399 (1995).

166. Goto, T. et al. Local secretory immunoglobulin $A$ and postimmunization gastritis correlate with protection against Helicobacter pylori infection after oral vaccination of mice. Infect. Immun. 67, 2531-2539 (1999).

167. Renegar, K.B. \& Small, P.A., Jr. Passive transfer of local immunity to influenza virus infection by IgA antibody. J. Immunol. 146, 1972-1978 (1991).

168. Takase, H., Murakami, Y., Endo, A. \& Ikeuchi, T. Antibody responses and protection in mice immunized orally against influenza virus. Vaccine 14, 1651-1656 (1996).

169. Phalipon, A. et al. Monoclonal immunoglobulin A antibody directed against serotype-specific epitope of Shigella flexneri lipopolysaccharide protects against murine experimental shigellosis. J. Exp. Med. 182, 769-778 (1995).

170. Bomsel, M. et al. Immunization with HIV-1 gp41 subunit virosomes induces mucosal antibodies protecting nonhuman primates against vaginal SHIV challenges. Immunity 34, 269-280 (2011). 
171. Duval, M., Posner, M.R. \& Cavacini, L.A. A bispecific antibody composed of a nonneutralizing antibody to the gp41 immunodominant region and an anti-CD89 antibody directs broad human immunodeficiency virus destruction by neutrophils. J. Virol. 82, 4671-4674 (2008).

172. Valerius, T. et al. Fc alphaRI (CD89) as a novel trigger molecule for bispecific antibody therapy. Blood 90, 4485-4492 (1997).

173. Deo, Y.M., Sundarapandiyan, K., Keler, T., Wallace, P.K. \& Graziano, R.F. Bispecific molecules directed to the Fc receptor for IgA (Fc alpha RI, CD89) and tumor antigens efficiently promote cell-mediated cytotoxicity of tumor targets in whole blood. J. Immunol. 160, 1677-1686 (1998).

174. Valerius, T. et al. Activated neutrophils as effector cells for bispecific antibodies. Cancer Immunol. Immunother. 45, 142-145 (1997).

175. Ma, J.K. et al. Characterization of a recombinant plant monoclonal secretory antibody and preventive immunotherapy in humans. Nat. Med. 4, 601-606 (1998).

176. Huls, G. et al. Antitumor immune effector mechanisms recruited by phage display-derived fully human lgG1 and IgA1 monoclonal antibodies. Cancer Res. 59, 5778-5784 (1999).

177. Stockmeyer, B. et al. Triggering Fc alpha-receptor I (CD89) recruits neutrophils as effector cells for CD20-directed antibody therapy. J. Immunol. 165, 5954-5961 (2000).

178. Dechant, M. \& Valerius, T. IgA antibodies for cancer therapy. Crit. Rev. Oncol. Hematol. 39, 69-77 (2001).

179. Stockmeyer, B. et al. Mechanisms of G-CSF- or GM-CSF-stimulated tumor cell killing by Fc receptor-directed bispecific antibodies. J. Immunol. Methods 248, 103-111 (2001).

180. Sundarapandiyan, K. et al. Bispecific antibody-mediated destruction of Hodgkin's lymphoma cells. J. Immunol. Methods 248, 113-123 (2001).
181. van Egmond, M. et al. Enhancement of polymorphonuclear cellmediated tumor cell killing on simultaneous engagement of $F_{c}$ gammaRl (CD64) and Fc alphaRI (CD89). Cancer Res. 61, 4055-4060 (2001).

182. Dechant, M. et al. Chimeric IgA antibodies against HLA class II effectively trigger lymphoma cell killing. Blood 100, 4574-4580 (2002).

183. Dechant, M. et al. Effector mechanisms of recombinant IgA antibodies against epidermal growth factor receptor. J. Immunol. 179, 2936-2943 (2007).

184. Zhao, J. et al. Recombinant human monoclonal igA antibody against CEA to recruit neutrophils to CEA-expressing cells. Oncol Res. 17, 217-222 (2008)

185. Guettinger, Y. et al. A recombinant bispecific single-chain fragment variable specific for HLA class II and Fc alpha RI (CD89) recruits polymorphonuclear neutrophils for efficient lysis of malignant $\mathrm{B}$ lymphoid cells. J. Immunol. 184, 1210-1217 (2010).

186. Lohse, S. et al. Recombinant dimeric IgA antibodies against the epidermal growth factor receptor mediate effective tumor cell killing. J. Immunol. 186, 3770-3778 (2011).

187. Bakema, J.E. \& van Egmond, M. Immunoglobulin A: a next generation of therapeutic antibodies? mAbs. 3, 352-361 (2011).

188. Bakema, J.E. et al. Targeting the immunoglobulin A Fc receptor (Fc alphaRI) on polymorphonuclear cells induces tumor cell killing through autophagy. J. Immunol. 187, 726-732 (2011).

189. Martin-Orozco, N. et al. Thelper 17 cells promote cytotoxic $T$ cell activation in tumor immunity. Immunity 31, 787-798 (2009).

190. Pelletier, M. et al. Evidence for a cross-talk between human neutrophils and Th17 cells. Blood 115, 335-343 (2010).

191. Scapini, P. et al. The neutrophil as a cellular source of chemokines. Immunol. Rev. 177, 195-203 (2000). 